\title{
Laboratorio móvil de educación artística: El Bus Arte Rodante. La expresión en movimiento*
}

\author{
Mobile artistic education laboratory: \\ The Rolling Art Bus. Expression in motion
}

\author{
Beatriz Eugenia Chaparro $^{1}$, Edwin Fernando Bravo $^{2}$, Nataly Becerra Vergara ${ }^{\circledR}$
}

Para citar este artículo: Chaparro, B. E., Bravo, E. F., Becerra, N. (2019). Laboratorio móvil de educación artística: el bus arte rodante. La expresión en movimiento. Infancias Imágenes, 18(2). [259-267]

\section{Resumen}

Este artículo versa sobre el desarrollo del proyecto de investigación encaminado a la creación de un laboratorio móvil de educación artística, portador de insumos y elementos facilitadores de procesos para la experimentación con lenguajes artísticos en espacios comunitarios. Los talleres itinerantes fueron creados con aportes de la pedagogía Waldorf y fueron desarrollados con niños y niñas de un barrio periférico del municipio de Popayán. Se reflexiona sobre la incidencia de esta experiencia en el fortalecimiento de tejidos sociales desde la práctica de educadores artísticos que se reconocen como transformadores sociales.

Palabras clave: innovación educacional, educación artística, experimento educacional, infancia.
Recibido: 20-06-2018 - Aceptado: 16-07-2019

\begin{abstract}
This article chronicles the development of a research project aimed at the creation of a mobile laboratory of artistic education, a vehicle that carries supplies and other items that facilitate processes for the experimentation with artistic languages in community spaces. Itinerant workshops were created with contributions taken from the Waldorf pedagogy and were developed with children from the peripheral neighbourhood of the municipality of Popayán. We reflect on the influence of this experience in strengthening the social fabric by the practices of artistic educators who perceive themselves as social innovators.
\end{abstract}

Keywords: educational innovation, artistic education, educational experiment, childhood.

El artículo es una reflexión que se deriva del proyecto "Laboratorio móvil de educación Artística, el Bus Arte Rodante, la expresión en movimiento". Esta propuesta fue ganadora en la convocatoria 04C-2015 proyectos conjuntos UEES en innovaciones educativas, la cual está respaldada por Sistema General de Regalías y el Fondo de Ciencia, Tecnología e Innovación Universidad del Cauca. Una alianza estratégica entre la Fundación Universitaria de Popayán y la empresa de transportes Transpubenza Ltda. El proyecto se desarrolló desde diciembre 2016 hasta enero 2018.

1 Profesora de la Licenciatura en Educación Artística y Cultural de la Fundación Universitaria de Popayán. Politóloga, Universidad del Cauca. Especialista en Infancia, Cultura y Desarrollo, Universidad Distrital Francisco José de Caldas. Correo electrónico: chaparro@docente.fup.edu.co

2 Docente de Educación Especial en la Fundación para la Estimulación en el Desarrollo y las Artes (Fedar). Licenciado en Educación Básica con énfasis en Educación Artística. Correo electrónico: fernandobravo2604@gmail.com

3 Directora de la Corporación Voces y Semillas. Licenciada en Educación Básica con énfasis en Educación Artística. Estudiante de Especialización en Psicología Social. Correo electrónico: quilichao25@gmail.com 


\section{Introducción}

El laboratorio móvil de educación artística llamado "El Bus Arte Rodante, la expresión en movimiento" es un proyecto de investigación y desarrollo social generador de espacios móviles educativos de cultura y arte. Este pretende contribuir a la apertura de escenarios para encuentros y experiencias a través de lenguajes artísticos, con niñas y niñas de barrios periféricos. El programa piloto se desarrolló en el Valle del Ortigal, barrio ubicado en el suroccidental de Popayán, Cauca, Colombia. Este proyecto se centró en la función social que tiene el pedagogo desde las prácticas con lenguajes artísticos, un campo de acción que se caracteriza por la creatividad, la espontaneidad y su carácter universal. A partir de un diálogo que nace en el aula, alimentado de preguntas y proyecciones, se plantea la posibilidad de usar un bus y adecuarlo como laboratorio de experimentación artística y trabajo colaborativo para llegar a poblaciones que se encuentran en la periferia de la ciudad y que no tengan fácil acceso a estos espacios de formación. Arte rodante se consolida con una alianza estratégica universidad-empresa-Estado-sociedad (UEES), en coordinación de InnovAcción Cauca.

Como antecedente de esta experiencia a nivel nacional se encuentra la propuesta de intervención social Ilamado "Bibliobús", liderada por la secretaría de educación en Bogotá, Colombia; y nivel Latinoamérica, se encuentra una propuesta de interacción social Ilamada "Un Bibliobús para Cochabamba", en Bolivia.

En Colombia tenemos algunos referentes en la implementación de laboratorios con sustento en prácticas artísticas, uno de ellos es un trabajo realizado por Bocanegra, Castillo, Garzón y Romero (2015), en el que se ponen en tensión acciones y pensamientos en torno al cuerpo, a las prácticas artísticas, a la educación y al trabajo en comunidad.

Este tipo de proyectos han sido inspiradores para la creación de los talleres que fueron desarrollados en el marco de Arte Rodante. El aporte que este proyecto hace a la innovación educativa fue el pensarlo como un espacio móvil, un laboratorio dotado con elementos e insumos básicos para poner en funcionamiento talleres de educación artística; incluyendo también una biblioteca infantil que pudiera desplazarse y funcionar de forma itinerante.

El proyecto Arte Rodante acompañó a la comunidad del Valle del Ortigal en procesos relacionados con la convivencia y la apropiación del espacio comunitario por parte de la población infantil. De igual manera, se generaron momentos, donde las prácticas lograron construir un vínculo desde lo social y lo comunitario. Este trabajo buscó aportar a los procesos de organización que vienen desarroIlando los pobladores desde su llegada al barrio en el año 2014, entre los cuales están la apertura de espacios para generar otras posibilidades de relación entre la población infantil, dando cabida a reflexiones sobre su contexto y la exploración de otras formas expresivas. Arte rodante buscaba conectar a los niños con el mundo del arte, de la sensibilidad estética y la reflexión de sus mundos e historias propias. Los talleres se sustentan en el teatro, un lenguaje que trabaja con la interrelación de las artes: en él se reúnen la literatura, la música la pintura, la danza, el canto el mimo; a la par que los divierte, va desarrollando en los niños una formación humanista.

\section{Un laboratorio móvil}

Partamos de la definición de laboratorio móvil. Es importante tener en cuenta qué es y cómo funciona, puesto que de ahí se toman elementos fundamentales que aportan a la construcción de una práctica respetuosa con el trabajo propuesto. Para ello, se toma que la definición general de un laboratorio es:

Un lugar que se encuentra equipado con los medios necesarios para llevar a cabo experimentos, investigaciones o trabajos de carácter científico o técnico. En un sentido más amplio, la noción de laboratorio se refiere a cualquier lugar o realidad en la cual se elabora o se experimenta. (Universidad Veracruzana, 2017)

Sin embargo, la noción de laboratorio surge en el campo del arte muy recientemente. En nuestro país esta se ve enmarcada en el nacimiento de los laboratorios de investigación-creación del Ministerio de Cultura (MinCultura) en el 2010. Según sus lineamientos, los laboratorios pueden ser espacios 


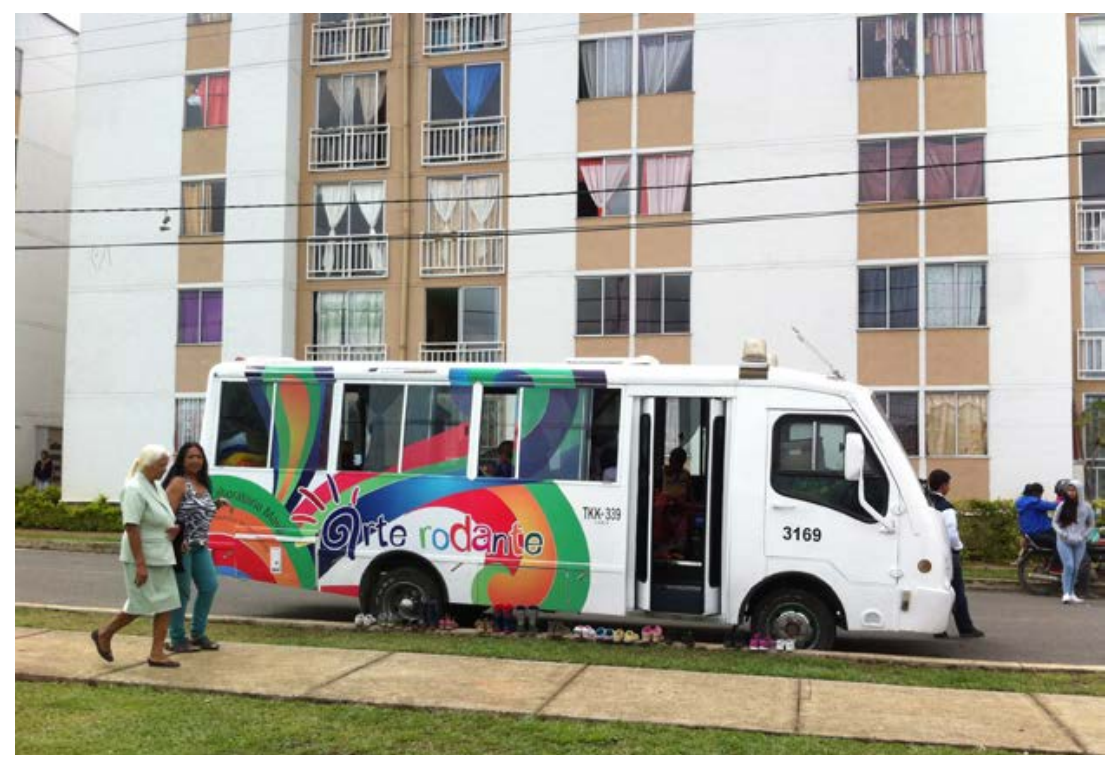

Figura 1. Laboratorio Móvil de Educación Artística, Arte Rodante en el Valle del Ortigal.

Fuente: Andrés Felipe Montenegro (2017).

de educación no formal que articulan temas como la democracia artística, el tejido de relaciones entre diversas instituciones de la región, pensamiento y experiencia. Arte Rodante apuesta por una educación artística incluyente, que genere espacios donde el respeto por la diversidad del ser humano sea tal que se constituya como sustento creativo, aportando al fortalecimiento del tejido social desde el derecho a la participación y creación de espacios culturales y artísticos teniendo en cuenta las experiencias de los participantes como el motor de la producción. "La formación en este marco de referencia se entiende como un derecho a la creación, a la creación como conocimiento y al conocimiento como creación, con evidentes repercusiones en la construcción y simbolización de las subjetividades personales y colectivas" (MinCultura, 2010. anexo5 p.1)

Existen definiciones interesantes que nacen de la reflexión de laboratorios artísticos colaborativos, por ejemplo, el término "colaboratorio", entendido como un emplazamiento sin paredes o "sin muros", un punto de encuentro y espacio de colaboración entre académicos, investigadores, estudiantes y público en general interesado en la conformación de espacios de aprendizaje en red, flexibles y participativos (Machal-Cajigas, 2004). El diseño de Arte Rodante como un laboratorio móvil permitió la experimentación con lenguajes artísticos tanto de los niños y niñas que participaron en los talleres itinerantes, como de los creadores del proyecto. En este sentido, se convierte en una práctica pedagógica que abre espacios para la reflexión del docente que considera importante descentralizar la educación artística de los monopolios culturales y académicos, entendiéndose como disciplinas que transforman relaciones sociales que proyectan cambios en la convivencia en el día a día de la comunidad. El laboratorio Arte Rodante permite la circulación del conocimiento, cuestionando los paradigmas de las jerarquías y la verticalidad de los papeles entre los sujetos que participan, vivenciando la educación artística como una alternativa de aprendizaje abierta e inclusiva. Como lo menciona Jiménez:

El desarrollo emocional apropiado de un ser humano, desde su infancia, es lo que permite que se construya fundado en la solidaridad y en la cooperación que, como criterios de nuestra cultura latinoamericana, es lo que distingue con relación a otras culturas que pregonan la individualidad, la competitividad. (Jiménez, 2011 p. 45)

El hacer en la experimentación está íntimamente relacionado con la construcción y transformación 
del entramado social. Esta apuesta por una educación integral desde una perspectiva inclusiva y multicultural, donde la educación artística tiene el reto de fortalecer y consolidarse el propio acervo cultural y, a la vez, ofrecer las herramientas necesarias para que una persona pueda leer y leerse desde sus diferentes contextos y realidades (Rodríguez, 2011).

La praxis de los lenguajes artísticos puede ser considerada también un camino de vivencias introductorias a oficios en los que existe la transformación de materiales con un fin, y se gesta un proceso sustentado en la experiencia de niños y niñas motivados por su propia imaginación y creatividad; un abanico de posibilidades para ser aplicados en su cotidianidad, sorteando de manera asertiva las dificultades que se les puedan presentar. Entendemos asertividad como la expresión directa de los propios sentimientos, necesidades, derechos legítimos u opiniones, sin ningún tipo de violencia hacia los demás.

Este proyecto propició la alianza entre universidad y empresa, logrando la interacción dinámica entre dos instituciones que, a pesar de tener un objeto social diferente, se encontraron en el marco de la Responsabilidad Social. Es así como un bus que estaba al servicio público de pasajeros fue transformado en un escenario con los insumos necesarios para darle vida a un laboratorio móvil de educación artística ${ }^{4}$.

\section{La expresión en movimiento: Artes Escénicas como estrategia de aprendizaje}

El hombre es menos auténtico cuando habla por sí mismo. Dale una máscara y te dirá la verdad.

Oscar Wilde

Cinco baúles de colores Ilamativos sirven de mobiliario interior del bus y portan los insumos que facilitan la práctica y el desarrollo de los talleres. En cada uno encontramos materiales estratégicamente puestos al alcance de los niños, instrumentos musicales, juegos didácticos, libros, pinturas, telas,

4 Tal como se puede evidenciar en el siguiente link: https://www. youtube.com/watch? $v=$ MQIOFuDXnw8 etc.; elementos para experimentar y aprender. Arte Rodante está dotado de una planta de energía que le da autonomía y permite conectarse en cualquier espacio. Es gracias a ella que funcionan aparatos eléctricos como: proyector de video, luces, computador portátil y cabina de sonido. Estos elementos posibilitan la proyección de material audiovisual y la producción de puestas en escena.

En el programa piloto se desarrollaron 4 módulos de educación artística, los cuales apuntan a la creación escénica en donde interactúan lenguajes artísticos como: música, dibujo y pintura, además de actividades relacionadas con lectura y juegos. Se utiliza el interior del bus y se aprovechan otros espacios para crear posibilidades para el trabajo en salones comunales y parques.

Cuando el ser humano se expresa, se extrae o pone de manifiesto pensamientos, emociones, ideas, fantasías, imaginaciones, sentimientos que condensan el sentido de nuestra vida, valiéndose del gesto, el grito, el llanto, la risa, la palabra, el dibujo, la pintura, el sonido musical, el movimiento corporal, la forma modelada; entendidos como medios generales de la expresión, que son los mismos que utiliza para enriquecer su experiencia, apropiarse de su contexto, vivirlo y transformarlo. El acceso a estos medios y la capacidad de aplicarlos con amplitud y flexibilidad determina la riqueza y calidad de las formas expresivas. "la expresión humana pone de manifiesto el contenido subjetivo de nuestra relación objetiva con el mundo. Es la vida individual, la conciencia, que se manifiesta significativamente" (Hernández, 2006 p. 12).

La presencia de las artes escénicas en la vida del ser humano permite el reconocimiento de sus debilidades y fortalezas, las cuales se van desarrollando a lo largo de su vida y dan cuenta de lo que cada uno es. Estas son una vía de comunicación directa que, aunque no cuenta verdades absolutas, sí entrega elementos para que cada persona construya su verdad. "En el arte no existe ninguna verdad universal. Una verdad es aquello cuyo contrario también es verdadero" (Wilde, 2001, p. 111).

En las experiencias de vida hay una relación profunda con las artes escénicas; en ella hay conflicto, se dan soluciones, se imagina otros mundos que no 

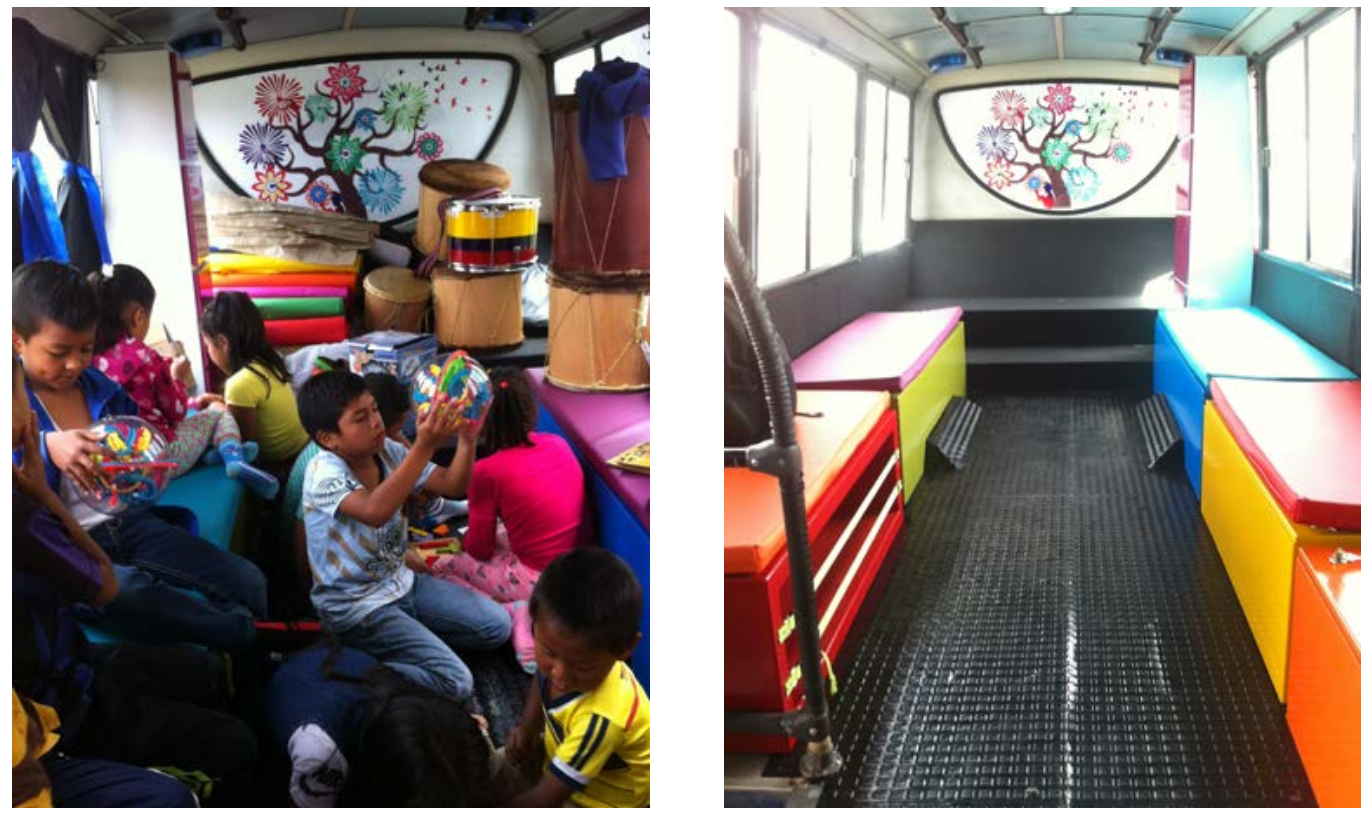

Figuras 2 y 3. Interior del laboratorio móvil.

Fuente: Andrés Felipe Montenegro (2017).

se pueden comunicar en lo cotidiano. "Todo lo que le sucede a otro le sucede a uno. Todo lo que le sucede a uno le sucede a otro" (Wilde, 2001, p. 111).

La introducción a los juegos teatrales es estratégica, ya que actúa como generador de la expresión creativa natural que todo ser trae consigo, lo que estimula tanto las cualidades como los valores sociales, éticos y estéticos. Arte Rodante se convierte en escenario móvil de experiencias y aprendizajes colectivos dotado de las herramientas para la creación de un montaje teatral, teniendo en cuenta el contexto social, las emociones, ideas, sueños, dudas, miedos e inquietudes de los participantes.

Arte Rodante desarrolló los talleres en diciembre. Este contexto permitió realizar diferentes actividades que llevaron a una reflexión con los niños sobre la Navidad; cómo se concibe, se vivencia en sus familias y el barrio. Son recurrentes las historias de accidentes con pólvora y de cómo muchos de sus allegados han sido víctimas de quemaduras con

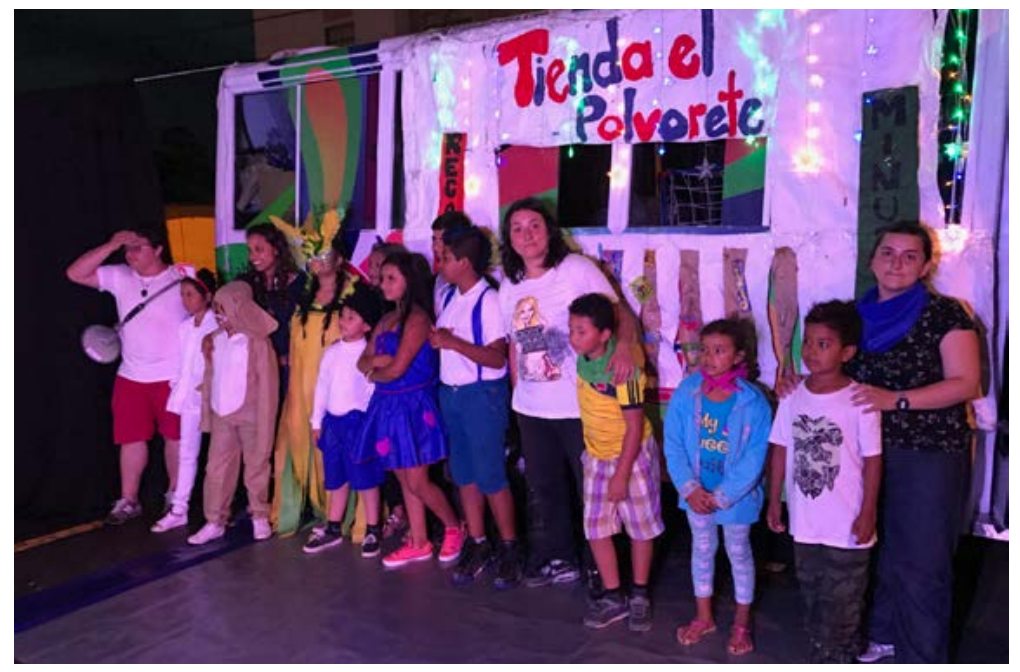

Figura 4. Montaje escénico Pum pum polvorete porque la pólvora no es un juguete. Valle del Ortigal.

Fuente: Clara Elisa López (2017). 
este elemento. Esta temática permite la creación de un guion titulado: Pum pum polvorete, porque la pólvora no es un juguete. Obra de carácter pedagógico y preventivo que articuló lenguajes artísticos como la plástica (dibujo y pintura) y la música en la puesta en escena con los niños y niñas del Valle del Ortigal.

Para los creadores de Arte Rodante es primordial la educación artística en la vida de los niños. El laboratorio móvil se diseña como un espacio facilitador de prácticas artísticas donde se articulan lenguajes como: dibujo, pintura, música, juegos didácticos y teatro. Los talleres contribuyen al espíritu creativo de los participantes y al desarrollo social de una comunidad que se involucra con sus niños en la puesta en escena final. La educación artística debe ser pertinente en los procesos de aprendizaje desde la infancia.

El imaginario social apunta a considerar la educación artística como "simples manualidades" que poco o nada aportan al desarrollo integral de los

264 seres humanos, olvidando la importancia de las artes en la transformación social.

El Ministerio de Educación Nacional (MEN) en los lineamientos curriculares de la educación artística y los programas que tienen la educación artística como énfasis o área del conocimiento, han emprendido acciones para favorecer la visión del área como un conjunto de conocimientos y habilidades indispensables en la vida del hombre; no como complemento sino como fundamento de formación que posibilita el crecimiento integral, aportando desde sus diferentes enfoques a la construcción del ser humano creativo y sensible con el entorno.

De acuerdo con el MEN, la educación artística se puede considerar como:

Un área del conocimiento que estudia [...] la sensibilidad mediante la experiencia (experiencia sensible) de interacción transformadora y comprensiva del mundo, en la cual se establece y se valora la calidad de la vida, cuya razón de ser es eminentemente social y cultural, que posibilita el juego en el cual la persona transforma expresivamente, de maneras impredecibles, las relaciones que tiene con los otros y las representa significando la experiencia misma. (2010, p. 33)
Esta área asume la realidad circundante, la sensibilidad humana y la expresión como una triada fundamental en la vida. Cuando los niños tienen contacto vivencial con las artes, fortalecen su capacidad creadora, concebida desde la característica que tiene el ser humano para resolver problemas de su vida cotidiana. "Lo que hace el arte es dar conciencia a las emociones, sensaciones y todos los conflictos que el ser humano tiene dentro; es un sistema completo que se trabaja desde temprana edad" (ABC del bebé, s.f.), así es como se pretende estimular y cultivar primordialmente el desarrollo de la sensibilidad en los niños y las niñas a través de un proyecto como el laboratorio móvil de educación artística.

\section{Arte Rodante, un proyecto social}

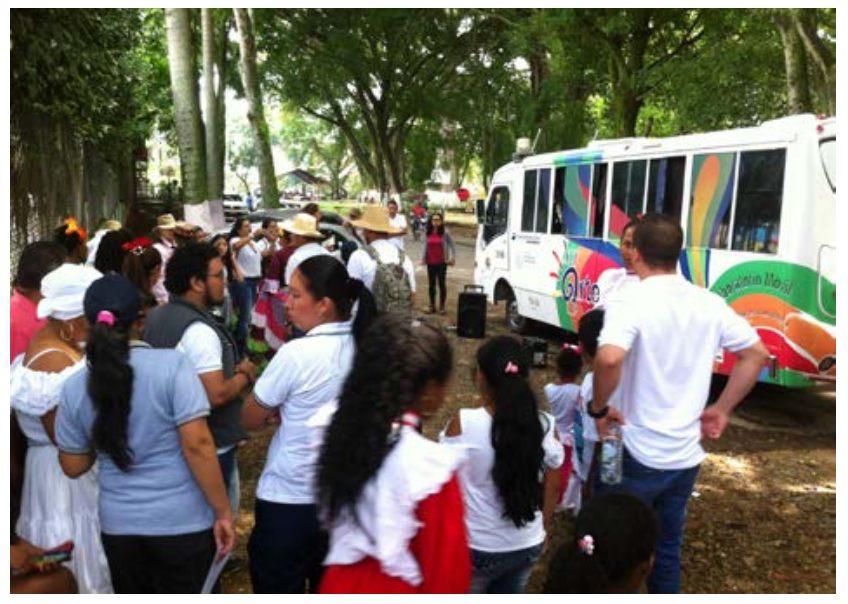

Figura 5. Presentación Arte Rodante en espacio comunitario.

Fuente: Andrés Felipe Montenegro (2017).

Al salir del aula a las comunidades se rompe uno de los paradigmas del sistema educativo tradicional: pensar que solo se aprende encerrado en cuatro paredes, memorizando datos, reproduciendo discursos que han sido legitimados como conocimiento o verdades absolutas. La educación con aprendizaje significativo va mucho más allá, trasciende a aprender por convicción, curiosidad y amor. Por ello, el docente actúa como un guía que acompaña un proceso, pero los principales actores son ellos, la comunidad. La formación del maestro en educación artística permite tener una mirada holística; además de ser incluyente, crítico, reflexivo y sensible ante 
las situaciones de su contexto, sabe que la educación artística va más allá de una producción manual, busca el desarrollo de la capacidad creadora a partir de la experimentación, fortaleciendo así procesos de construcción personal.

Trabajar con comunidades permite conocer nuestro entorno local y regional, además el intercambio cultural y social que se presenta trae consigo aprendizajes para la vida, se aprende desde sus saberes y costumbres. Es allí donde se encuentra la estrecha relación entre las artes y las comunidades. Donde un diálogo, una entrevista o una observación da para que el maestro de educación artística se aproxime a sus narrativas, experiencias y conozca sus fortalezas y necesidades; para pensar desde las luces de la educación artística qué se puede hacer para transformar realidades de índole personal o colectiva.

Es importante salir de un aula de clase haciendo práctico, móvil y significativo el conocimiento, la intención no es formar artistas, sino intentar aportar a su desarrollo personal como seres creativos, capaces de reconocer, solucionar y transformar los problemas que aquejan sus entornos. Además de lo anterior, permite que las personas conozcan el sentido de la educación artística; como ya se mencionó anteriormente no es solo dibujar, pintar o hacer una manualidad, trasciende de manera directa en los comportamientos que se desarrollan en cada uno de los individuos que forman parte de una sociedad.

\section{De la mano con Rudolf Steiner y la pedagogía Waldorf}

Reflexionar sobre la pedagogía es un ejercicio que todo maestro debe hacer continuamente. Buscar e indagar sobre este tema, más que un "gusto", es un deber; es desde ahí que se logra nutrir el quehacer docente, con las diferentes corrientes que alimentan la pluralidad de prácticas de un maestro.

Para lograr entrar en sintonía con lo que es la pedagogía Waldorf hay que tener en cuenta diferentes aspectos en el ámbito personal y profesional. Uno de los más importantes es abrir plenamente los sentidos y estar en disposición de escuchar y percibir un lenguaje más profundo desde los conceptos que propone; la filosofía acompaña generalmente las diferentes reflexiones y textos que a lo largo de la historia se han escrito sobre este tema.

A la luz de la pedagogía Waldorf se concibe la educación como "un obrar artístico" que posibilita encontrar caminos más sensibles y humanos en la labor de la educación, donde debe estar ligado el arte al entorno afectivo del ser humano y así conseguir un trabajo que impacte positivamente en su pensar, en su sentir y sobre todo en su hacer.

Quienes conocen de educación Waldorf y han logrado investigar y conectarse con esta corriente del saber son conscientes de la importancia que tiene en el ser humano la biografía, es decir, su trasegar por la tierra y sobre todo las vivencias propias. Es por esta razón que en esta pedagogía se habla de "septenios", es decir, periodos de siete años en los que el individuo sufre transformaciones de índole física e interior, para ser más exactos en el porqué de esta división de la vida humana: "es el tiempo que emplean los distintos cuerpos sutiles del ser humano en su correspondiente maduración" (Crotoggini, 1998, p. 75). Así, según Steiner, “en cada septenio el cuerpo humano se renueva completamente, lo que conlleva unas nuevas cualidades anímicas y espirituales que han de ser conocidas y atendidas". Visto de este modo, la educación del niño se hace con mucho respeto por estos septenios que acompañan su desarrollo. Esta manera de concebir al ser humano es muy especial y no busca encasillar dicho desarrollo; por el contrario, la pedagogía Waldorf le apuesta a generar acompañamientos desde la libertad de experimentar y enfatizar en la búsqueda de armonía del ser.

En el programa piloto de Arte Rodante participaron niños entre los 5 y 14 años. Por ello, tuvimos en cuenta las características de estas etapas como sustento teórico y práctico de los talleres.

El primer septenio que aborda el ser humano en su paso por la tierra es el de los 0 a los 7 años y es un periodo en el cual el niño es concebido como un órgano sensorio, es decir, que las impresiones recibidas en su alma y en su corazón durante esta época serán una impronta en su vida. Un ideal en esta etapa del camino es "el mundo es bello". La importancia de los adultos en el camino de la vida de los niños se ve reflejada en este principio. Los talleristas de Arte Rodante reconocen la enorme responsabilidad 
que afrontan y por esto vincularon a las familias en el proceso creativo buscando sensibilizar sobre el desarrollo íntegro y armonioso de sus hijos.

Una palabra que defina este septenio sería imitación, es un momento en donde los niños y las niñas tienen una enorme conexión con el adulto, ellos logran percibir más a fondo el sentir y esto se refleja en su hacer. Se podría afirmar que los niños en esta etapa de su vida imitan tanto como respiran.

Arte Rodante propone trabajar con rondas, el canto, la música pentatónica para favorecer el desarrollo de los órganos, el movimiento, el juego y el encuentro con los materiales que brinda la naturaleza como, semillas, piedras, plantas, lana, madera, entre otros son vitales en un espacio donde estén inmersos niños en esta edad.

Los talleres se alimentan y crean espacios desde una de las posiciones más fascinantes que tiene dicha pedagogía, la cual es la de proponer que el docente siempre debe estar en constante reflexión tanto de sus prácticas como de su hacer.

El segundo septenio está constituido entre los 7 y los 14 años de edad; el $60 \%$ de los participantes de los talleres estaba en este periodo. El ideal básico que se destaca en este septenio es la belleza. El niño de esta edad es un poeta, hay que ayudarlo para que se exprese (Crotoggini, 1998). Visto de esta manera, en este septenio hay algo muy importantes que desde la educación se debe entrar a trabajar lo bello y artístico imaginativo.

Todo lo que se le da en este septenio al niño alimenta su alma, el sonido, la pintura, la música, el canto, los lenguajes artísticos están para cumplir este cometido y el niño lo vivencia de una manera muy positiva.

Según Crottogini, "lo podemos ver saltar, correr, reír, llorar... sus sentimientos se expanden, también lo veremos muchas veces triste y desconcertado sin saber por qué" (1998, p. 31), los sentires que afloran en este momento de la vida del niño son más que normales en el proceso de construcción de su personalidad. El proyecto Arte Rodante brinda herramientas que posibilitan un conocerse mejor y sentirse inmersos en el mundo, actividades en las que se asuma un papel protagónico, resaltar las capacidades y acompañar los defectos desde un punto de vista más positivo, teniendo en cuenta algunas de las opciones que se tiene en el ámbito educativo para acompañar esta característica del segundo septenio.

\section{Las huellas de los talleres}

Las artes escénicas como dinamizadores de habilidades expresiones y sentimientos, son sin duda uno de los pilares fundamentales del quehacer pedagógico en el proyecto Arte Rodante. El teatro permite el encuentro de otros lenguajes artísticos como la música, la plástica, el texto, la expresión corporal; además de la construcción de conceptos y sentires desde las diferentes áreas del saber que al articularlas se convierten en sinergia de posibilidades para que los niños y las niñas los vivencien como medios de aprendizaje.

El potenciar la fantasía creadora desde el teatro, los movimientos corporales, la expresión, la acción de percibir al otro desde diferentes miradas, son procesos necesarios para las relaciones humanas. Esa comunicación sin palabras, en donde su cuerpo sea el medio para expresarse debe ganar validez, tanto en los espacios académicos como sociales.

El juego dirigido en la propuesta de trabajo en los espacios de formación itinerante permitió el acercamiento entre los participantes y los talleristas, creando vínculos afectivos y otros canales de expresión y comunicación.

El juego crea su propio mundo, donde existe otro orden, otro espacio, otro tiempo, un orden sin fin ni intención externa al propio juego, una actividad reversible, que puede volver a empezar siempre, eliminando los inevitables encadenamientos y consecuencias inexorables del sentido lineal y acumulativo de los actos. (Huizinga, citado por Bernabeu y Goldstein, 2012, p. 54)

La creación libre y espontánea en la puesta en escena final despertó en los niños del valle del Ortigal momentos de convivencia sana, pues se creó un ambiente alegre y democrático, respetuoso en las relaciones con sus pares en la cotidianidad. Momentos significativos como: el encuentro con el otro, el diálogo, la comunicación diversa, la sensibilidad y creatividad se convirtieron en elementos importantes en su construcción de identidad y la relación con su entorno. Niños, padres de familia y talleristas se 
vincularon activamente en la producción de la obra. Cada uno cumplió una función, de acuerdo con sus intereses o destrezas. Se tuvo en cuenta a los niños y niñas como ejes dinamizadores de las prácticas, actividades en las cuales aprenden y descubren, llevándolos a un desafío por investigar y recrear.

Las prácticas artísticas posibilitaron un trabajo pedagógico centrado en una dimensión humana creativa, que cuestiona y replantea el valor de la cognición como único potencial para lograr procesos de aprendizajes significativos. Estas acciones artísticas resignifican la mirada tradicional de los procesos de formación, ya que son dinámicas y generan experiencias constructivas. En el ejercicio pedagógico con los niños y las niñas del Valle del Ortigal se permite la exploración de mundos infantiles y se reconoce a los niños como creadores y no solo consumidores de cultura mediática.

La alianza estratégica que se generó entre el sector privado y la academia debe continuar aportando a procesos de educación, arte y cultura en el municipio de Popayán. Esta experiencia permitió el encuentro significativo entre los niños y niñas de la comunidad y los facilitadores de los talleres. En la vivencia artística se interiorizaron procesos de aprendizaje desde la sensibilidad, la cual canalizó la parte emotiva de los niños y niñas en un hacer que tiene en cuenta la significación propia como un componente fundamental en la vida de los seres humanos. Proyectos con estas características resignifican la mirada tradicional de los procesos de formación humana en la sociedad.

\section{Referencias}

ABC del bebé (s.f.). La importancia de la expresión artística en los niños. Recuperado de https://www.abcdelbebe.com/nino/la-importancia-de-la-expresion-artistica-en-los-s-11048
Bernabeu, N. y Goldstein, A. (2012). Creatividad y aprendizaje. Bogotá: Ediciones de la U; Narcea.

Bocanegra, M., Castillo, D., Garzón, M. y Romero, M. (2015). Laboratorios de creación en artes: Prácticas colaborativas en comunidades específicas. Bogotá: Colectivo Otro. Asociación Nacional de Investigación en Artes Visuales (ANIAV). https://doi.org/10.4995/ aniav.2015.1263

Crottogini, R. (1998). La tierra como escuela: la biografía humana. Buenos Aires: Indugraf.

Hernández, D. (2006). Notas de clase. Literatura y Mundos Infantiles. Especialización en Infancia, Cultura y Desarrollo. Universidad Distrital Francisco José de Caldas. Bogotá.

Jiménez, A. (2011). Pedagogía de la creatividad y la lúdica. Emociones, inteligencia y habilidades secretas. Bogotá: Magisterio.

Machal-Cajigas, A. (2004). El colaboratorio: Un nuevo enfoque hacia la investigación científica.

Ministerio de Cultura de la República de Colombia (2010). Lineamientos laboratorios de investigación creación. Artes visuales - Dirección de Artes. Bogotá.

Ministerio de Educación Nacional de la República de Colombia (2010). Orientaciones pedagógicas para la educación artística. Bogotá: Magisterio.

Rodríguez, J. (2011). Entrevista realizada a Julia Rodríguez, maestra y fundadora del Colegio Unidad Pedagógica. Bogotá.

Universidad Veracruzana (2017). Laboratorio. Recuperado de https://www.uv.mx/veracruz/cess/ servicios/laboratorio/

Wilde, O. (2001). Aforismos y paradojas. Selección de textos y traducción: Efraín Sánchez. Bogotá: Villegas Editores. 